\title{
Optimization of Liquid Ammonia Treatment for Enzymatic Hydrolysis of Miscanthus sinensis Anderss
}

\author{
Liping Zhang, Hehuan Peng, Qinling Yu, Ying Zhang, Zhijun Wang, Xianwei Tang \\ School of Engineering, Zhejiang A\&F University, Linan, China \\ Email: 253455672@qq.com
}

Received 21 April 2015; accepted 10 July 2015; published 17 July 2015

\begin{abstract}
Miscanthus biomass yield high, high photosynthetic efficiency, fast growth, easy breeding, widely distributed, is suitable as raw materials for the production of fuel ethanol. In this paper, the method of the pretreatment of liquid ammonia for Miscanthus, using the pretreatment of liquid ammonia to overcome biomass recalcitrance, adding cellulase enzyme, and the monosaccharide content is determined by using high performance liquid chromatography (HPLC). Effect of pretreatment process on the enzyme solution effect of awn, conducts the research to the water processing rate, temperature, residence time, amount of ammonia, the amount of $\mathrm{H}_{2} \mathrm{O}_{2}$ parameters. Data shows that, in the moisture content of $80 \%$, temperature $130^{\circ} \mathrm{C}$, loading amount of ammonia $2: 1$, residence time $10 \mathrm{~min}$, the glucan and xylan enzyme conversion rate are $73.23 \%$ and $73.28 \%$ respectively. After a mass balance, dry base mans per $100 \mathrm{~g}$ can get glucose $28.96 \mathrm{~g}$ and xylan 17.25 g.
\end{abstract}

\section{Keywords}

Miscanthus, Liquid Ammonia Pretreatment, Enzymatic Hydrolysis, Fuel Ethanol

\section{Introduction}

With the energy crisis becomes more prominent, the development and utilization of new energy have becoming imminent. The bio-energy has become a hot energy in today's world. Renewable energy fuel ethanol is much cleaner compared to fossil fuel.

Miscanthus (Miscanthus sinensis Anderss) belongs to angiosperms Gramineae. It is herbaceous perennial and tall plant, composing stable community [1]. Miscanthus plants blossom after heading, leaf stem ratio increasing, high cellulose content, especially the stalk, crude cellulose content in 50\% above, and to the Miscanthus as the most. According to the determination, the total content of cellulose in Miscanthus is $80.75 \%$ [2], it is very suitable as biological energy materials.

The main components of the plant cell wall are cellulose, hemicellulose, lignin. Lignin interior besides have strong hydrogen bonding connection, but also with the semi cellulose by covalent bond to form stable LCCs.

How to cite this paper: Zhang, L.P., Peng, H.H., Yu, Q.L., Zhang, Y., Wang, Z.J. and Tang, X.W. (2015) Optimization of Liquid Ammonia Treatment for Enzymatic Hydrolysis of Miscanthus sinensis Anderss. Journal of Power and Energy Engineering, 3, 26-32. http://dx.doi.org/10.4236/ipee.2015.37005 
These structure characteristics make lignocellulose hydrolysis recalcitrant exist strong [3] [4]. Although many microbes can decompose separate existence of the cellulose, but because in cell wall cellulose by lignin protection, so it is not susceptible to microbial degradation of [5] [6]. The most critical step in the production of fuel ethanol by lignocellulosic materials is the pre-processing of material [7], it can decide the preprocessing step of cellulose and hemicellulose conversion rate and cost [8]. The pretreatment methods mainly include: acid pretreatment, alkali pretreatment, high temperature hot water method, acid catalysis method, high temperature hot water steam blasting method and ammonia fiber explosion method, each treatment effect have advantages and disadvantages [9]-[12]. Through the cycle of ammonia explosion treatment of corn straw can improve the enzymatic hydrolysis rate, maximum glucan yield reaches $85.7 \%$ [13]. Presented in this paper is put forward on the basis of the AFEX liquid ammonia pretreatment of this new technology, experiment for influence in different conditions of enzymatic hydrolysis rate, experimental results obtained the highest saccharification rate of fuel ethanol, resulting in lower production costs and higher yield [14]. The total conversion of Erianthus enzymolysis of glucan and xylan rates were $69.34 \%$ and $82.60 \%$ with liquid ammonia pretreatment method, than not pretreatment of raw materials were increased by $573 \%$ and $1056 \%$, the yield is 8 times of monosaccharide untreated [15].

\section{Materials and Methods}

\subsection{Experimental Materials}

Miscanthus used in this study was grown in Lin'an County (30.11, 119.38), Zhejiang Province, China, harvested in June, 2012. After harvesting the whole plant awn of the ground part is cut into $1-2 \mathrm{~cm}$ long strip, The Miscanthus samples were dried to $<10 \%$ moisture (total weight basis) using a $40^{\circ} \mathrm{C}$ oven, then the micro grinder (FZ102) crushed into 50 - 100 mesh powder. After mixing evenly, using instrument using water (MA35, Sartorius) to measure the moisture content, labeled with a plastic bag sealed, placed in the refrigerator and temperature is set to $-20^{\circ} \mathrm{C}$ in storing spare.

For high performance liquid chromatography (HPLC) analysis of glucose, xylan standard are purchasing Sigma-Aldr ICH company, the purity was more than $99 \%$.

The addition of hydrolytic enzymes for cellulose (NovozymeNS50013), $\beta$-glucosidase (Novozyme NS50010) and xylanase (Shandong chanson Biotechnology Co. Ltd.).

\subsection{Experimental Methods}

\subsubsection{Acid Solution on the Material Composition Analysis}

Experimental determination of determining carbohydrate awn material and insoluble lignin (Klason lignin) components using LAP002 and LAP003 methods. Using acid hydrolysis method aims to determine biomass carbohydrates and insoluble lignin (Klason lignin) content of component in raw material. Concrete steps are first weighing awn materials stem based $0.3 \mathrm{~g}$, adding $72 \%$ sulfuric acid $3+0.01 \mathrm{~mL}$, keep $2 \mathrm{~h}$ in $30^{\circ} \mathrm{C} \pm 1^{\circ} \mathrm{C}$ water bath, adding deionized water $84 \mathrm{~mL}$ (diluted to $4 \%$ sulfuric acid), in the $121^{\circ} \mathrm{C}$ autoclave in $1 \mathrm{~h}$, after vacuum filtration, the filter paper on solids drying to constant weight, using high performance liquid chromatography (high performance liquid chromatography, HPLC) determine sugar content, and the calculation of glucan, xylan, Arabia sugar percentage. Solid quality calcined to remove ash quality after the acid insoluble lignin content, namely Klason lignin content.

\subsubsection{Liquid Ammonia Pretreatment Method (LAT)}

Pretreatment with LAT: take quantitative raw materials according to a dry basis, according to the set water content by adding quantitative water, place in a reaction kettle full mix, and set the heating temperature. Quantitative liquid ammonia injection liquid cylinders, heat to about $50^{\circ} \mathrm{C}$ and then ammonia injected into the reaction kettle, rapidly heat to the set temperature and keep a certain predetermined time. Subsequent release of ammonia, remove the processing of raw materials and take pre drying in a ventilated cabinet, after $24 \mathrm{~h}$, remove it to the oven (lower than $45^{\circ} \mathrm{C}$ ) drying about $12 \mathrm{~h}$ (moisture content below 10\%), weighed and measured to determine the water content, determine the biomass yield after the pretreatment of raw materials, labeled and placed in the ice box refrigeration spare $-20^{\circ} \mathrm{C}$. The choice of technological parameters of LAT optimization respectively: temperature, moisture content, residence time, ammonia dosage. 


\subsubsection{Enzymatic Hydrolysis}

Enzymatic hydrolysis with the relevant rules of LAP009, the reaction volume increased to $15 \mathrm{~mL}$ (the original $10 \mathrm{~mL}$ ). Weigh $0.15 \mathrm{~g}$ dextran equivalent biomass use electronic scale into enzymolysis bottle, by calculation, sequentially add $750 \mathrm{ul}$ buffer, $150 \mathrm{ul}$ antibiotics, after adding, take the enzyme solution bottle into table, and set the temperature of $50^{\circ} \mathrm{C}$, the speed of $150 \mathrm{r} / \mathrm{min}$ pre heating $1 \mathrm{~h}$. Then remove the enzyme solution bottle, add cellulase $38 \mathrm{ul}, \beta$-glucosidase $48 \mathrm{ul}$, xylanase $15 \mathrm{ul}$. Add the amount of cellulase was $15 \mathrm{FPU} /(\mathrm{g}$ equivalent of dextran), $\beta$-glucosidase $64 \mathrm{pNPGU} / \mathrm{g}$. Added into the table started to enzymatic hydrolysis and to record the start time of enzymatic hydrolysis. Enzymatic hydrolysis of the sampling interval time were $24 \mathrm{~h}, 72 \mathrm{~h}$ and $144 \mathrm{~h}$.

The enzyme solution sampling: with $1000 \mathrm{uL}$ pipetting Gun take $1 \mathrm{~mL}$ enzyme samples, inject into centrifuge tube, take into the heating constant temperature heater temperature is set as $100^{\circ} \mathrm{C} \mathrm{in} 20 \mathrm{~min}$, and then put it into the speed for centrifugal 15,000 r/min centrifuge disposable needle in $5 \mathrm{~min}$, and filter, then take into HPLC sample bottle, put into cold storage of the spare $-20^{\circ} \mathrm{C}$.

\subsubsection{The Quantitative Analysis of Sugar}

The quantitative determination of monosaccharides by HPLC method, the determination of glucose, xylan and Arabia sugar content, and then converted into the glucan, xylan or Arabia in raw materials. The experiment used for Agilent Technologies 1200 Series (with auto injector), using differential refractive index detector, the column was BioRad's HPX-87H, the mobile phase was $0.005 \mathrm{~mol} / \mathrm{L}$ dilute sulfuric acid, the flow rate is $0.5 \mathrm{~mL} /$ min, the column temperature was $50^{\circ} \mathrm{C}$, sample size $15 \mu \mathrm{L}$. For high performance liquid chromatography (HPLC) analysis of the control group's (sample) glucose, xylan, Arabia sugar were purchased from Sigma-Aldrich company, the purity was more than $99 \%$.

\subsubsection{The Calculation of the Hydrolysis Rates and Total Sugar Yield}

Enzymatic hydrolysis rate was actually obtained similar monosaccharide content of monosaccharide content and raw material ratio in (or a similar ratio of dextran, chitosan) by enzymatic hydrolysis rate as an example, the calculation formula is:

$$
d=\frac{g * 15 / 1000 * 162 / 180}{0.375 * c / 100} * 100
$$

where: $g$ is the concentration of glucose in the enzyme solution.

$c$ is the raw material of cellulose (dextran) percentage content, obtained by acid hydrolysis method.

15 express that the enzyme solution is the total $15 \mathrm{~mL}, 162 / 180$ express that mass conversion of dextran after polymerization lose water, 0.375 express that dry basis of biological (g).

\section{The Results and Analysis}

\subsection{Miscanthus Component Analysis}

By Table 1 can see, Miscanthus of dextran (cellulose) content of 39.54\%, the content of xylan content is $23.56 \%$, the two together $63.10 \%$.

\subsection{Effects of Moisture Content and Components on the Enzymatic Hydrolysis}

Effect of moisture content on the enzymatic hydrolysis rate as shown in Figure 1. The experiment to control the temperature of $130^{\circ} \mathrm{C}$, pretreatment of residence time is $10 \mathrm{~min}$, liquid ammonia and raw material ratio of 2:1. The results show that, when the moisture content is $80 \%$ and $150 \%$, the conversion rate of glucan enzyme is high, $72 \mathrm{~h}$ sampling the enzymolysis rate were $67.07 \%$ and $68.02 \%$, with the untreated $24.13 \%$ respectively improved $178 \%$ and $182 \%$. Xylan enzymatic conversion rate is high in water content is $80 \%$ and $100 \%$, respectively $73.28 \%$ and $73.77 \%$, with the untreated $14.07 \%$ respectively improved $421 \%$ and $424 \%$. The experiment-

Table 1. Compositional analysis of Miscanthus.

\begin{tabular}{cccc}
\hline Component (\%) & Glucan & Xylan & Klason lignin \\
\hline Miscanthus & $39.54 \pm 0.74$ & $23.56 \pm 1.51$ & $22.85 \pm 0.78$ \\
\hline
\end{tabular}




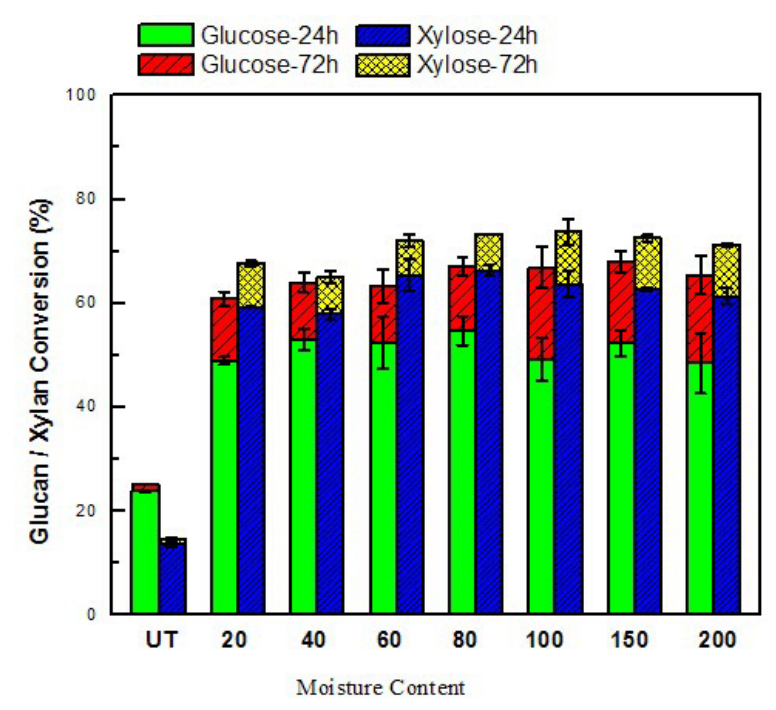

Figure 1._Effects of moisture content on glucan/xylan conversion of LATtreated Miscanthus sinensis Anderss.

tal results show that the moisture content is $100 \%$, the enzyme solution $144 \mathrm{~h}$, dextran and xylanase hydrolysis rates were $74.54 \%$ and $77.66 \%$. As can be seen from the graph, in the range of parameters, variation of water content for Miscanthus conversion rate influence is not very big.

\subsection{Effects of Temperature and Components on the Enzymatic Hydrolysis}

The experiment will control the moisture content in $80 \%$, pretreatment of residence time is 10 min, liquid ammonia and raw material ratio of 2:1, temperature of solution for the influence of the rate of enzyme as shown in Figure 2. The experimental results show that, dextran and xylanase hydrolysis rate improved with the increase of temperature basically, and the conversion rate increased with the temperature rise is small. Research has shown that, glucose production needs higher reaction temperature [16]. When the temperature is $170^{\circ} \mathrm{C}$, conversion rate of glucan hydrolysis is the highest, enzymatic hydrolysis of $72 \mathrm{~h}$ sampling rate is $74.84 \%$, with the untreated $24.13 \%$ increased 2.1 times. Xylan enzyme hydrolysis conversion rate at the temperature of $170^{\circ} \mathrm{C}$ is the highest, $75.17 \%$, increased by $434 \%$ with the untreated $14.07 \%$. The experimental results show that, the temperature of $170^{\circ} \mathrm{C}$, enzyme $144 \mathrm{~h}$, dextran and xylanase hydrolysis rates were $81.49 \%$ and $79.15 \%$.

\subsection{Effects of Ammonia Loading and Components on the Enzymatic Hydrolysis}

Ammonia is used to increase the removal of grass lignin content [17], so ammonia loading is an important parameter of liquid ammonia pretreatment. Many scholars show that Rice straw and starch rich corn green is the best carrier for 1:1 [18]. And the best loading amount of ammonia of bamboo is 1:2 [14]. Results from the study can be seen, for different biomass materials, the optimal amount of load of ammonia is not the same. So it is very important for the loading amount of ammonia Miscanthus optimization. The amount of ammonia loading refers to the use of volume and biomass feedstock ammonia dry based mass ratio. The experiment conditions were: $80 \%$ moisture content, temperature fixed at $130^{\circ} \mathrm{C}$, residence time of $10 \mathrm{~min}$. As you can see from Figure 3, with loading amount of ammonia increase from 0.5:1 to 3:1, the conversion rate of glucan and xylan increase slowly, and to increase the proportion to 5:1, there has a slight decline. When the load of ammonia concentration of 3:1, $72 \mathrm{~h}$ sampling of glucan and xylan hydrolysis rates were $78.19 \%$ and $76.03 \%, 144 \mathrm{~h}$ sampling of glucan and xylan hydrolysis rates were $84.26 \%$ and $79.83 \%$. So the loading amount of ammonia is not the bigger the better, but from a certain extent, increase the content of ammonia will promote the enzymolysis effect.

\subsection{Effects of Residence Time and Components on the Enzymatic Hydrolysis}

The experimental temperature fixed at $130^{\circ} \mathrm{C}, 80 \%$ moisture content, ammonia and raw material ratio of $2: 1$, the residence time solution for the influence of the rate of enzyme as shown in Figure 4. When the residence time is 
$5 \mathrm{~min}$, glucan and xylan conversion rate is the lowest, $72 \mathrm{~h}$ sampling were $58.86 \%$ and $66.19 \%$, and When the residence time is $10 \mathrm{~min}$, glucan and xylan conversion rate reach the highest point, glucan and xylan conversion rates were $73.23 \%$ and $72.20 \%$, compare with the conditions of residence time is 5 min increase by $24 \%$ and $9 \%$. So the effect of increasing residence time on conversion rate of dextran is large and xylan is small, the residence time of 10 min for the glucan and xylan conversion rates are $73.23 \%$ and $72.20 \%$, the conversion rate is relatively high. Considering energy consumption and cost, choose 10 min residence time as the optimum pretreatment conditions.

\subsection{Mass Balance}

Pretreatment and enzymatic hydrolysis mass balance process as shown in Figure 5. In the preprocessing optimal conditions $\left(80 \%\right.$ moisture content, temperature fixed at $130^{\circ} \mathrm{C}$, load the amount of ammonia $2: 1$, residence time is $10 \mathrm{~min}$ ), cellulase dosage of $15 \mathrm{FPU} /(\mathrm{g}$ equivalent dextran), $100 \mathrm{~g}$ dry Miscanthus enzyme $45.97 \mathrm{~g}$ can be obtained after $72 \mathrm{~h}$ of monosaccharide, without pretreatment materials available sugars as $11.57 \mathrm{~g}$, transformation rate increase 2.97 times. Miscanthus enzyme the highest glucose and xylan yield were $73.23 \%$ and $73.20 \%$ after pretreatment of LAT.

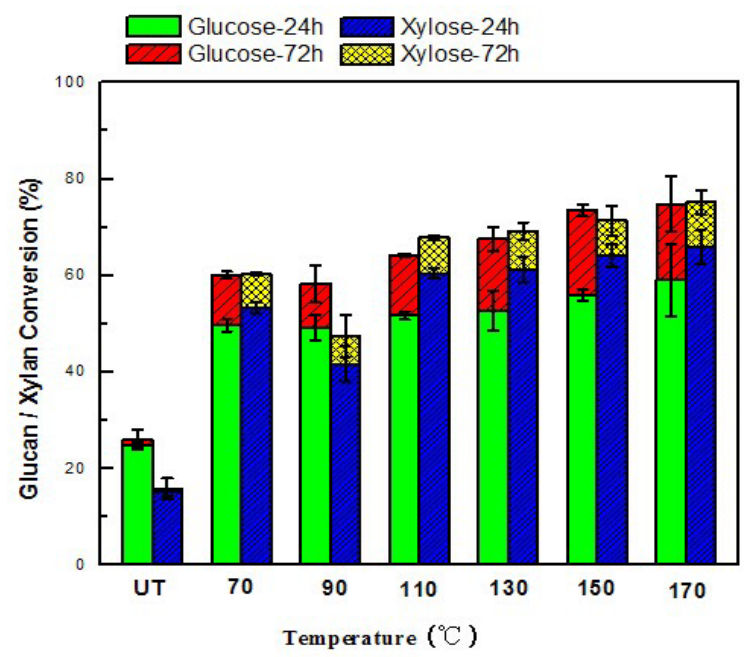

Figure 2. Effects of temperature on glucan/xylan conv-ersionof LAT-treated Miscanthus sinensis Anderss.

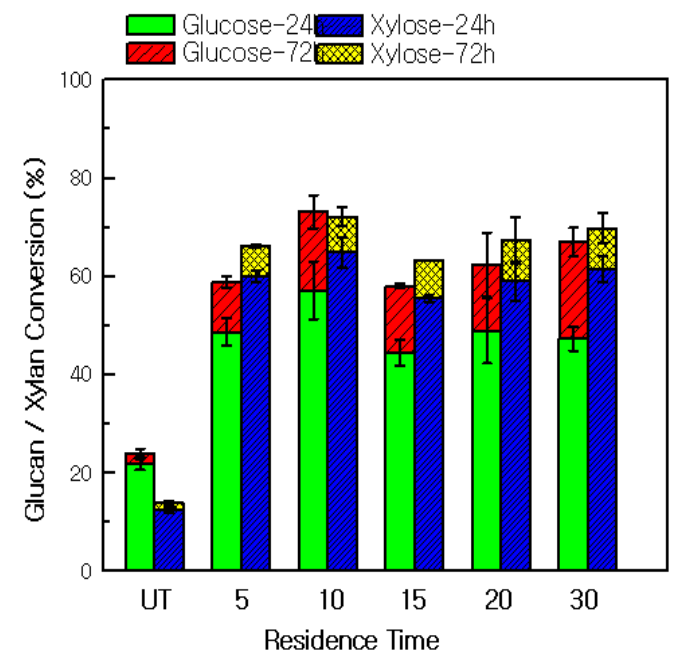

Figure 3. Effects of ammonia loading on glucan/xylan conversion of LAT-treated Miscanthus sinensis Anderss. 


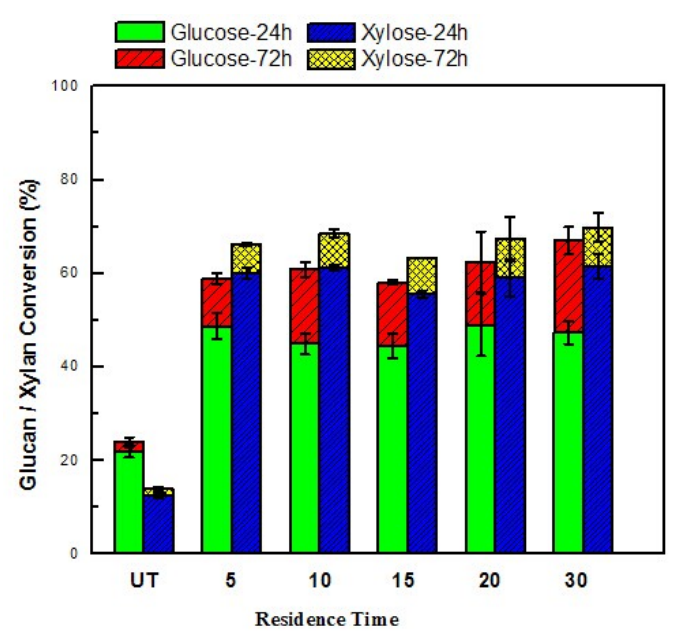

Figure 4. Effects of time residence on glucan/xylan conversion of LAT-treated Miscanthus sinensis Anderss.

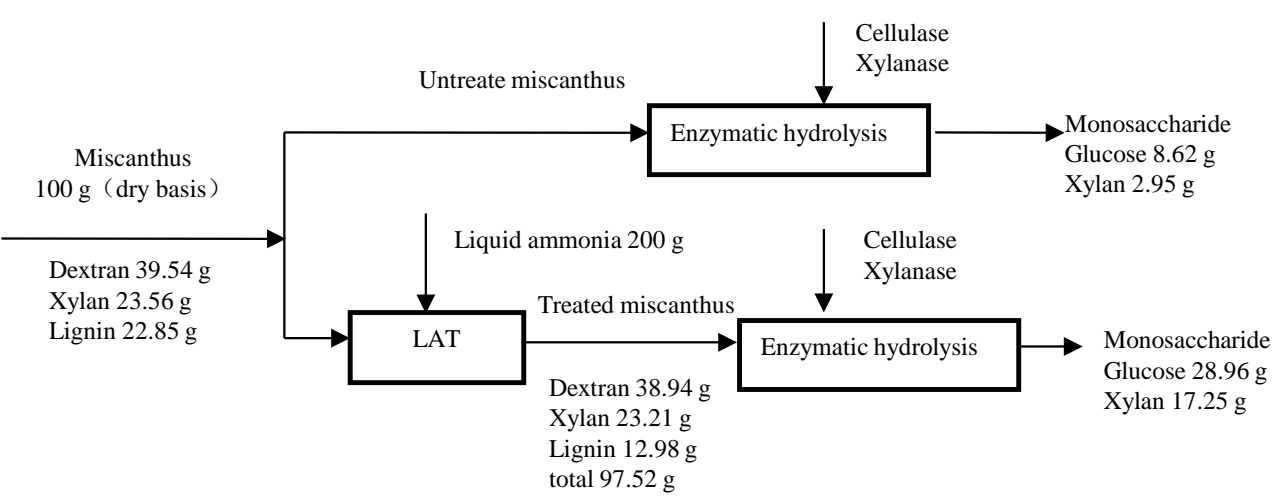

Figure 5. Flow chart of mass balance during pretreatment and hydrolysis process for Miscanthus.

\section{Conclusion}

On the condition of Miscanthus LAT processing optimize moisture content, temperature, loading amount of ammonia and residence time, equilibrium of raw materials of enzymatic hydrolysis rate and consumption, draw the optimum conditions is $80 \%$ moisture content, temperature fixed at $130^{\circ} \mathrm{C}$, loading amount of ammonia $2: 1$, residence time $10 \mathrm{~min}$, at this time, glucan and xylan enzymatic conversion $73.23 \%$ and $73.20 \%$, after the mass balance, per 100 g dry Miscanthus can obtain glucose 28.96 g, xylanase 17.25 g.

\section{References}

[1] Yao, X.J. (2006) Agricultural Resources and Sustainable Development of Agriculture. Journal of Chengdu University: Social Sciences Edition, 5, 48-49.

[2] Zhao, N.X. and Xiao, Y.F. (1990) Anhui Province Miscanthus Plant Resources and Its Exploitation and Utilization. Wuhan Botany Research, 4, 375-379.

[3] Liu, C. and Wyman, C. (2003) The Effect of Flow Rate of Compressed Hot Water on Xylan, Lignin, and Total Mass Removal from Corn Stover. Industrial Engineering Chemistry Research, 42, 5409-5416. http://dx.doi.org/10.1021/ie030458k

[4] Anvar, U. and Buranov, G.M. (2008) Lignin in Straw of Herbaceous Crops. Industrial Crops and Products, 28, 237259. http://dx.doi.org/10.1016/j.indcrop.2008.03.008

[5] Li, G.X. and Zhang, F.S. (2000) Solid Waste Composting and Organic Fertilizer Production. Chemical Industry Press, Beijing.

[6] Xi, B.D., Liu, H.L., et al. (2002) Composting of Cellulose and Lignin Biodegradation Research Status. Techniques and 
Equipment for Environmental Pollution Control, 3, 19-23.

[7] Sánchez, Ó.J. and Cardona, C.A. (2007) Trends in Biotechnological Production of Fuel Ethanol from Different Feedstocks. Bioresource Technology, 11, 1-25.

[8] Balat, M., Balat, H. and Ǒz, C. (2008) Progress in Bioethanol Processing. Progress in Energy and Combustion Science, 34, 551-573. http://dx.doi.org/10.1016/j.pecs.2007.11.001

[9] Yu, Z., Li, G.Y., et al. (2008) Comparison of Different Pretreatment for Arundo donax Saccharification on the Production of Fuel Ethanol Effect. Guizhou Agricultural Sciences, 36, 117-119.

[10] Mosier, N., Wyman, C., Dale, B., et al. (2005) Features of Promising Technologies for Pretreatment of Lignocellulosic Biomass. Bioresource Technology, 96, 673-686. http://dx.doi.org/10.1016/j.biortech.2004.06.025

[11] Geddes, C.C., Nieves, I.U. and Ingram, L.O. (2011) Advances in Ethanol Production. Current Opinion in Biotechnology, 22, 312-319. http://dx.doi.org/10.1016/j.copbio.2011.04.012

[12] Kumar, P., Barrett, D.M., Delwiche, M.J., et al. (2009) Methods for Pretreatment of Lignocellulosic Biomass for Efficient Hydrolysis and Biofuel Production. Industrial Engineering Chemistry Research, 48, 3713-3729. http://dx.doi.org/10.1021/ie801542g

[13] Zhang, C., et al. (2013) Recycled Aqueous Ammonia Expansion (RAAE) Pretreatment to Improve Enzymatic Digestibility of Corn Stalks. Bioresource Technology, 138, 314-320. http://dx.doi.org/10.1016/j.biortech.2013.03.091

[14] Shao, Q.J., Chundawat, S.P., Krishnan, C., et al. (2010) Enzymatic Digestibility and Ethanol Fermentability of AFEXTreated Starch-Rich Lignocellulosics Such as Corn Silage and Whole Corn Plant. Biotechnology for Biofuels, 3, 12. http://dx.doi.org/10.1186/1754-6834-3-12

[15] Liu, J.J., Peng, H.H., et al. (2013) Erianthus Enzymatic Conversion of Fermentable Sugars Liquid Ammonia Pretreatment and Parameters Optimization. Journal of Biological Engineering, 29, 233-241.

[16] Boonmanumsin, P., Treeboobpha, S., Jeamjumnunja, K., et al. (2012) Release of Monomeric Sugars from Miscanthus sinensis by Microwave-Assisted Ammonia and Phosphoric Acid Treatments. Bioresource Technology, 103, 425-431. http://dx.doi.org/10.1016/j.biortech.2011.09.136

[17] Rodríguez, H., Padmanabhan, S., et al. (2011) Addition of Ammonia and/or Oxygen to an Ionic Liquid for Delignification of Miscanthus. Bioresource Technology, 102, 7946-7952. http://dx.doi.org/10.1016/j.biortech.2011.05.039

[18] Zhong, C., Lau, M.W., Balan, V, et al. (2009) Optimization of Enzymatic Hydrolysis and Ethanol Fermentation from AFEX-Treated Rice Straw. Applied Microbiology and Biotechnology, 84, 667-676. http://dx.doi.org/10.1007/s00253-009-2001-0 